\title{
The line transect method for estimating densities of large mammals in a tropical deciduous forest: An evaluation of models and field experiments
}

\author{
K SURENDRA VARMAN and R SUKUMAR* \\ Centre for Ecological Sciences, Indian Institute of Science,Bangalore 560 012,India
}

MS received 18 October 1994; revised 23 February 1995

\begin{abstract}
We have evaluated techniques of estimating animal density through direct counts using line transects during 1988-92 in the tropical deciduous forests of Mudumalui Sanctuary in southern India for four species of large herbivorous mammals, namely, chital (Axis axis). sambar (Cervus unicolor). Asian elephant (Elephas maximus) and gaur (Bos gaurus)

Density estimates derived from the Fourier Series and the Half-Normal models consistently had the lowest coefficient of variation. These two models also generated similar mean density estimates. For the Fourier Series estimator, appropriate cut-off widths for analyzing line transect data for the four species are suggested. Grouping data into various distance classes did not produce any appreciable differences in estimates of mean density or their variances, although model fit is generally better when data arc placed in fewer groups. The sampling effort needed to achieve a desired precision (coefficient of variation) in the density estimate is derived. A sampling effort of $800 \mathrm{~km}$ of transects returned a $10 \%$ coefficient of variation on estimate for ehital; for the other species a higher effort was needed to achieve this level of precision. There was no statistically significant relationship between detectability of a group and the size of the group for any species. Density estimates along roads were generally significantly different from those in the interior of the forest, indicating that road-side counts many not be appropriate for most species.
\end{abstract}

Keywords. Line transect method; large mammals; wildlife census; tropical forest.

\section{Introduction}

Estimating the population size or density of an animal species in an area is fundamental to understanding its status and demography, and to plan for its management and conservation. In spite of the development of sophisticated statistical methods of sampling animal populations (Burnham et al 1980), their application to estimating densities in tropical forests is difficult mainly because of poor visibility and relatively low density of these populations resulting in inadequate sample sizes for statistically precise results. The practical difficulty of carrying out random sampling due to habitat topographic features is an additional constraint in sampling design.

Both direct and indirect methods of estimating mammal densities in tropical forests have been used (Barnes and Jensen 1987; Koster and Hart 1988; Varman 1988; Sale et a! 1990; Karanth and Sunquist 1992; Srikosamatara 1993; Varman et al 1995). Estimates based on indirect methods usually involve counting animal droppings, while direct methods use visual sightings of animals. Line transect

\footnotetext{
*Corresponding author.
} 
sampling is practical, efficient and relatively inexpensive for many biological populations (Anderson et al 1979; Burnham et al 1980; Buckland et al 1993). Although it has been extensively used in temperate regions for estimating densities for a variety of vertebrate taxa, one of the first rigorous applications of the method in a tropical forest was by Karanth and Sunquist (1992) to estimate densities of mammals.

In this paper we evaluate the line transect direct method of estimating animal densities and come up with recommendations on the choice of models for four large mammalian species in a tropical deciduous forest. In particular we explore the following questions:

(i) What are appropriate models and model parameters for data analysis?

Unlike sampling methods based on fixed-width transects, the line transect method does not assume that all objects within a specified width are detected. Rather the assumption is that objects on the line are seen with probability 1 and that the number of objects sighted away from the line decreases in some fashion. Underlying any continuous random variable, such as the detection distance, is a probability density function (PDF) (Burnham et al 1980). An appropriate model is fitted to the data to estimate the density of the object.

A robust model is one that is flexible enough to fit closely a wide variety of true PDF shapes (Burnham et al 1980). Various estimators are available including the Fourier Series, Exponential Power Series, Exponential Polynomial, Negative Exponential and Half-Normal.

For a chosen model, decisions have to be taken about several model parameters. For instance, we can specify a cut-off width or include sightings at all distances. If the cut-off width is too short the sample size may be limiting, whereas if there is no cut-off width the outliers may increase the variance of the density estimate. If sightings are grouped into distance class intervals (as opposed to using actual distance) a decision has to be taken about the number of distance classes and class intervals. To achieve smoothing, the data should be grouped into no more than about 10 class intervals (Burnham et al 1980).

(ii) How much sampling effort is necessary in order to arrive at a density estimate with acceptable confidence limits?

With constraints in time and resources for carrying out censuses, the optimum sampling effort to return density estimates with acceptable precision (coefficient of variation or confidence intervals) has to be decided. There is no method of arriving at this decision a priori, and pilot studies have to be carried out. Sampling efforts will vary between species, depending on abundance and detectability among other factors.

(iii) What is the influence of group size of a species on the detection function?

The detectability of a group of animals may depend on the size of the group. If the probability of detecting a larger group is higher this would lead to overestimation of the mean group sizes and the population densities (Drummer and McDonald 1987). In such a case, it is more appropriate to apply a bivariate model that corrects for this size bias (Drummer and McDonald 1987).

(iv) Can roads be used for estimating animal densities from vehicles?

In many situations an observer does not have sufficient time to devote to making 
ideal density estimates (for instance, when various other investigations also have to be carried out). In such cases, adequate number of sightings (sample size) of the species being censused is often a major constraint in obtaining satisfactory estimates.

An increase in sampling effort using vehicles for rapidly "transecting" a large area seems to be an option under such circumstances. However, sampling along roads introduces potential biases. In the first instance, driving in a vehicle along roads may disturb animals and perhaps drive them away before the observer has a chance of spoiling them. Secondly, there may be a bias in animal distribution along the road side. Certain species may be attracted towards roads or road-side clearings, while others may be repelled from roads or the sound of vehicles plying along these. The alignment of roads may be such that different habitats or topographical features may not be proportionately sampled. Roads are not straight lines and this may violate a basic assumption of line transect theory. Actually this is not a serious problem as long as the curvature is gentle (A P Gore, pers. comm.). Even if the line transect method cannot be applied to road-side counts, the data can be analysed using assumptions of a fixed-width transect.

\section{Materials and methods}

\section{$2.1 \quad$ Study area}

The study was carried out in Mudumalai Wildlife Sanctuary $\left(321 \mathrm{~km}^{2} .11^{\circ} 13^{\prime}\right.$ to $11^{\circ} 39^{\prime} \mathrm{N}$ and $76^{\circ} 27^{\prime}$ to $76^{\circ} 43^{\prime} \mathrm{E}$ ) in the Tamil Nadu state of southern India. The altitude varies from $485 \mathrm{~m}$ to $1266 \mathrm{~m}$ above sea level, with a general elevation of $900-1000 \mathrm{~m}$. A distinct rainfall gradient results in a variation in vegetation type from tropical semi-evergreen forest and moist deciduous forest through dry deciduous forest to dry thorn forest (Sukumar et al 1992). An area of $127 \mathrm{~km}^{2}$ (figure 1) comprising deciduous forest and dry thorn forest was selected for this study during 1988-92. Mudumalai supports a mammalian fauna typical of deciduous forests of peninsular India (Krishnan 1972; Nair et al 1977). Of these we selected four species of large herbivorous mammals, chital or spotted deer (Axis axis), sambar (Cervus unicolor), Asian elephant (Elephas maximus) and gaur (Bos gaurus) for the present study.

\subsection{Density estimation methods}

Based on vegetation types, the area was stratified into different habitat zones such as dry deciduous forest with tall grass $\left(32 \mathrm{~km}^{2}\right)$, dry deciduous forest with short grass $\left(16 \mathrm{~km}^{2}\right)$, moist deciduous forest $\left(33 \mathrm{~km}^{2}\right)$, thorn forest $\left(45 \mathrm{~km}^{2}\right)$ and riparian forest $\left(1.4 \mathrm{~km}^{2}\right)$. Transects lines were placed in these zones in a fashion that they sampled each zone in rough proportion to their areas.

2.2a Vehicle-based counts : During 1991. several game roads were traversed using a vehicle at a near-constant speed of $20 \mathrm{~km} / \mathrm{h}$. Seven routes were identified so as to cover all the habitat types in rough proportion to their areas. Total distance covered by vehicle transect was $967 \mathrm{~km}$ during the year. 


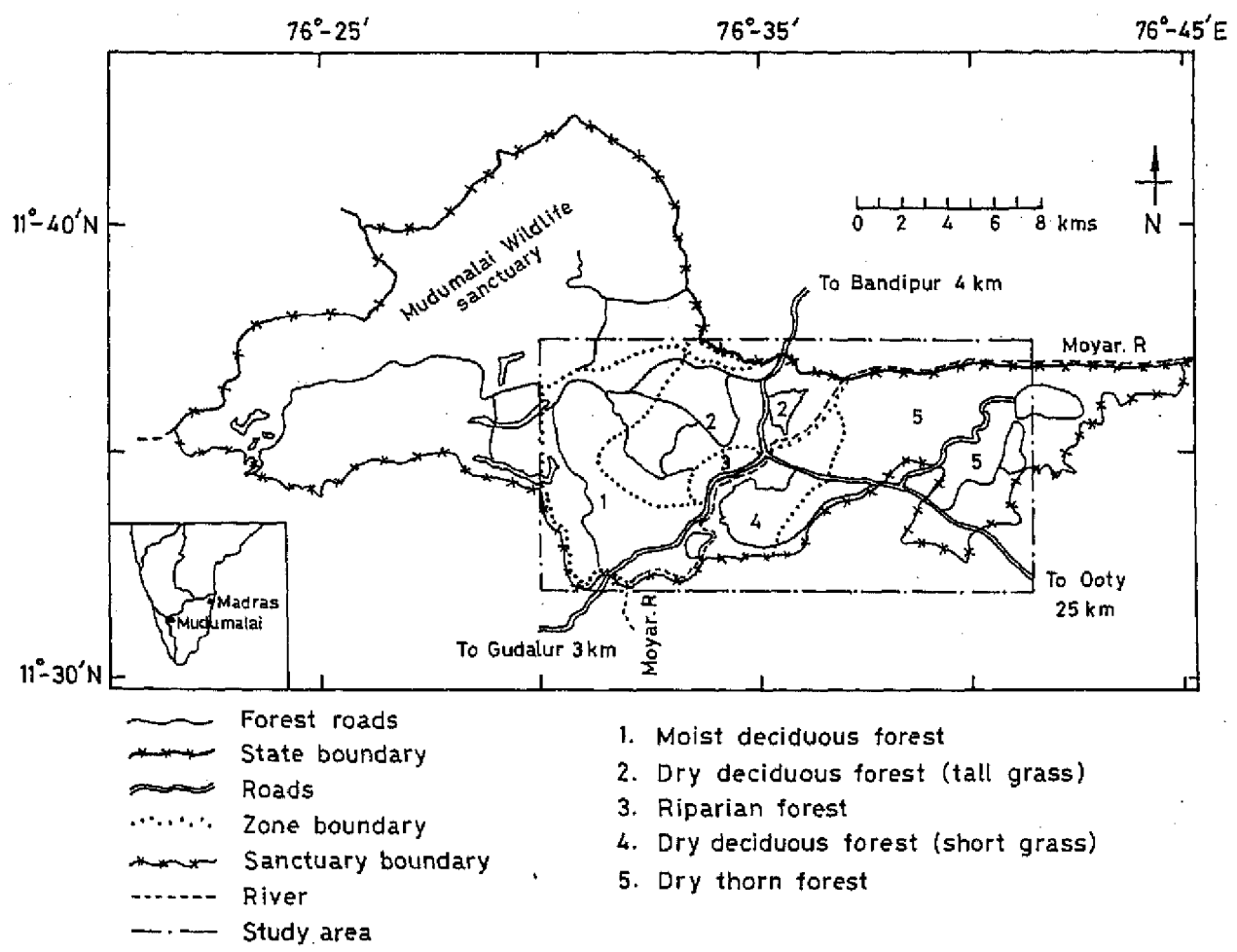

Figure 1. Map of the study area showing the locations of the five vegetation types or zones sampled,

2.2b Walking transect: Transects of two types were walked during 1988-92. (i) To study the distribution of animals along roads in the absence of a source of disturbance such as a vehicle, in four major zones $2 \mathrm{~km}$ each of two adjoining game roads were walked, in addition to walking a $2 \mathrm{~km}$ transect through the forest in between these roads. The idea was to compare density estimates along the roads with those inside the forest, (ii) Six permanent transect lines of 2-4 km were laid in different habitats and walked on a regular basis during 1991 and 1992. The total distance walked was $409 \mathrm{~km}$ per year.

Each transect was covered once in the morning $(07.00 \mathrm{~h}$ to $09.30 \mathrm{~h})$ and once in the evening $(16.00 \mathrm{~h}$ to $18.30 \mathrm{~h})$ each month. The transects were covered from opposite ends in order to minimize any bias arising from variation in animal activity with time. For each sighting the central location of the animal group was noted, and the perpendicular distance from this location to the transect line (or road) was recorded using a rangefinder (15 to $180 \mathrm{~m}$ range), at $10 \mathrm{~m}$ class intervals, in addition to details of group composition.

\subsection{Data analyses}

Densities of groups were computed using the program TRANSECT (Laake et al 1979, PC version by G White). A general form of the density estimator is given by

$$
D=\frac{n f(0)}{2 L}
$$


where $D$ is (he density of the object (or object clusters), $n$ is the number of objects detected, $L$ is the length of the transect line, and $f(0)$ is the probability density function of perpendicular distances evaluated at zero.

We first analysed the data using five models (Fourier Series, Exponential Power Series, Exponential Polynomial, Negative Exponential and Half-Normal) and used a $\chi^{2}$ goodness of fit test and the precision of the estimate $(\mathrm{CV})$ to evaluate the models. Subsequently, we used the Fourier Series model for examining model parameters in greater detail. To estimate animal density, the density of groups was multiplied by the mean group size. The standard error (SE) of the mean estimate was arrived at following Goodman (I960), and 1.96 SE taken as the 95\% confidence interval.

$$
\{\mathrm{SE}(D)\}^{2}=\left\{Y^{2} \times(\mathrm{SE}(Z))^{2}\right\}+\left\{Z^{2} \times(\mathrm{SE}(Y))^{2}\right\},
$$

where $\mathrm{Z}=$ density of groups $/ \mathrm{km}^{2}, Y=$ mean group size, and $D=$ density of individuals $/ \mathrm{km}^{2}$.

For the analysis, sightings were categorized into $20 \mathrm{~m}$ distance class intervals (from 0 to $200 \mathrm{~m}$ ). In order to determine the appropriate width and the number of distance classes to be used, we analysed data from 2 classes (i.e., a cut-off width of $40 \mathrm{~m}$ ) to 10 classes (up to $200 \mathrm{~m}$ ). We examined the percentage coefficient of variation as a function of cut-off width to determine the appropriate cut-off width.

In order to determine adequacy of sampling effort for achieving desired precision in the density estimate, we analysed the walking transect data cumulatively beginning with two months and proceeding up to 22 months. Trends in CV were plotted with increase in sampling effort (distance walked) to look at this relationship.

The influence of group size on detectability ("size bias") was tested using the program SIZETRAN (Drummer 1987). In this a bivariate detection function is used, by inserting a covariate $y$ into the univariate detection function through a ratio $x / y^{a}$, where $a$ (or $\alpha$ ) is the size-bias parameter. A value of $a=0$ implies that the size of a group has no influence on its detectability. An iterative procedure is used to arrive at the value of $a$, and a likelihood ratio used to test for significance of size-bias. As SIZETRAN did not provide a bivariate model for the Fourier Series estimator, we used a bivariate Half-Normal estimator in our analysis (in trials using various univariate models we found results from the Fourier Series and Half-Normal estimators to be similar).

\section{Results}

\subsection{Models and model parameters}

Typical shapes of the distribution of perpendicular distances of animal sightings, grouped into $20 \mathrm{~m}$ class intervals, are given for the four species in figure 2 . The shape of the distributions superficially suggests exponential decay. We however decided to fit several models to the data. Table 1 gives the results of density estimates, percentage $\mathrm{CV}$ and $\chi^{2}$ values of the different models fitted to the data, grouped into different number of distance classes and class intervals. The Fourier Series estimator generally estimates density with the lowest CV, followed closely 

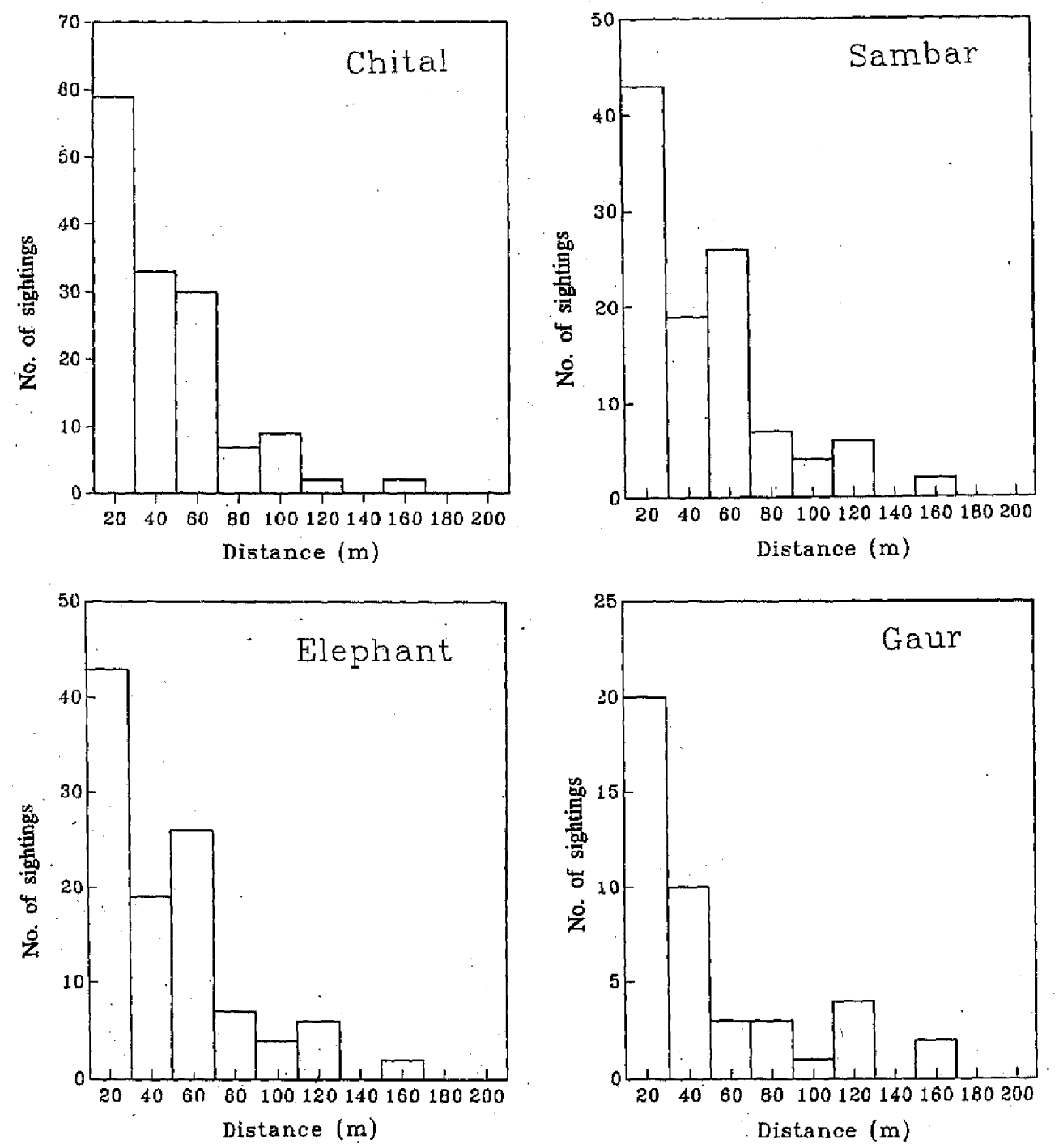

Figure 2. Distribution of perpendicular distances of sightings into $20 \mathrm{~m}$ class intervals for the four species of mammals.

by the Half-Normal model. With some exceptions, the density estimates are also the most similar for the Fourier Series and Half-Normal models. Among other estimators, the Negative Exponential consistently gives the highest density estimates for all species, except the gaur.

When the $\chi^{2}$ values are considered, it is seen that a statistically good fit $(P>0.05)$ for data of all species is obtained in the most instances with the Fourier Series model. The Half-Normal model also offers good fits for chital, sambar and elephant, and seems to fit data especially well for chital. For the gaur, the Half-Normal model consistently gives a poor fit, while the Negative Exponential model appears to be the best alternative to the Fourier Series. 


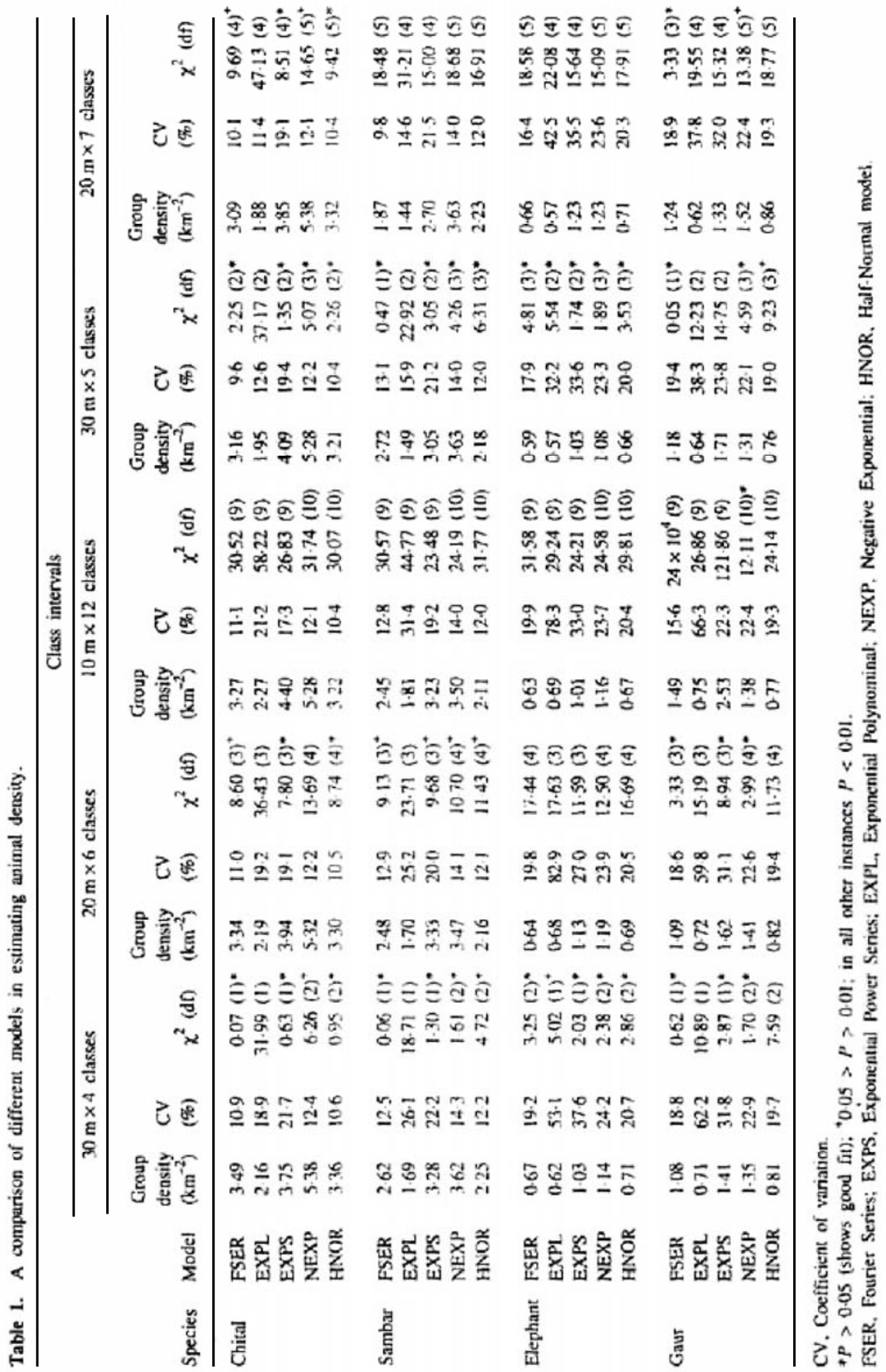


When results from the same data set are grouped into different classes and class intervals there is virtually no difference in estimates of density or $\mathrm{CV}$ for a given model for any of the four species (table 1). However, the $\chi^{2}$ values indicate that a better fit is obtained when data are grouped into fewer classes.

Figure 3 shows the relationship between CV of density estimate and various cut-off widths for the four species. For chital there is an appreciable reduction in $\mathrm{CV}$ when data were included up to a distance of $80 \mathrm{~m}$ (4 distance classes, sample size of 129 groups) but inclusion of data beyond $80 \mathrm{~m}$ does not necessarily increase the precision of the results. For sambar and elephant a reduction in CV generally continues up to $140 \mathrm{~m}$ ( 7 distance classes, 105 groups in sambar, 37 groups in elephant) beyond which the value fluctuates. For gaur the lowest $\mathrm{CV}$ is achieved at a cut-off width of $180 \mathrm{~m}$ ( 9 classes, 43 groups). The estimates of individual
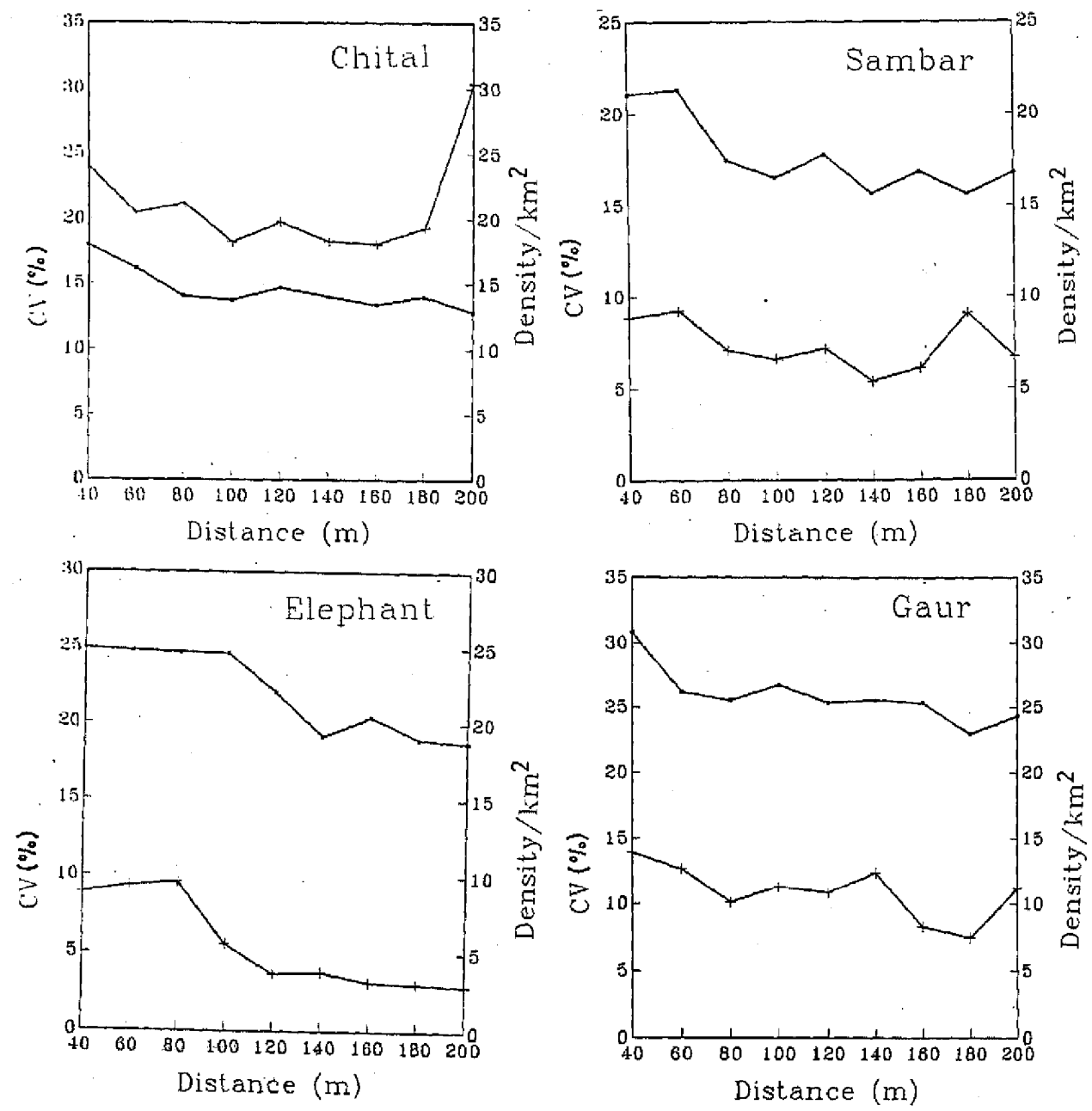

Figure 3. Trends in percentage coefficient of variation (CV) $(-\bullet-)$ and mean density (individuals $\left./ \mathrm{km}^{2}\right)(-+-)$ with different cut-off widths (in metres) for sighting data of the four mammalian species. 
density stabilize in the region of 120-200 m cut-off width for elephant and 100-180 $\mathrm{m}$ for chital (increasing appreciably when all data up to $200 \mathrm{~m}$ are used), while for sambar and gaur these fluctuate to a greater degree with different cut-off widths.

\subsection{Sampling effort and precision of estimate}

Figure 4 shows trends in $\mathrm{CV}$ and (cumulative) mean density estimates with increase in sampling effort (the sample sizes of sightings and the distance walked are given separately in table 2). A CV (on individual density) of $20 \%$ of the mean estimate
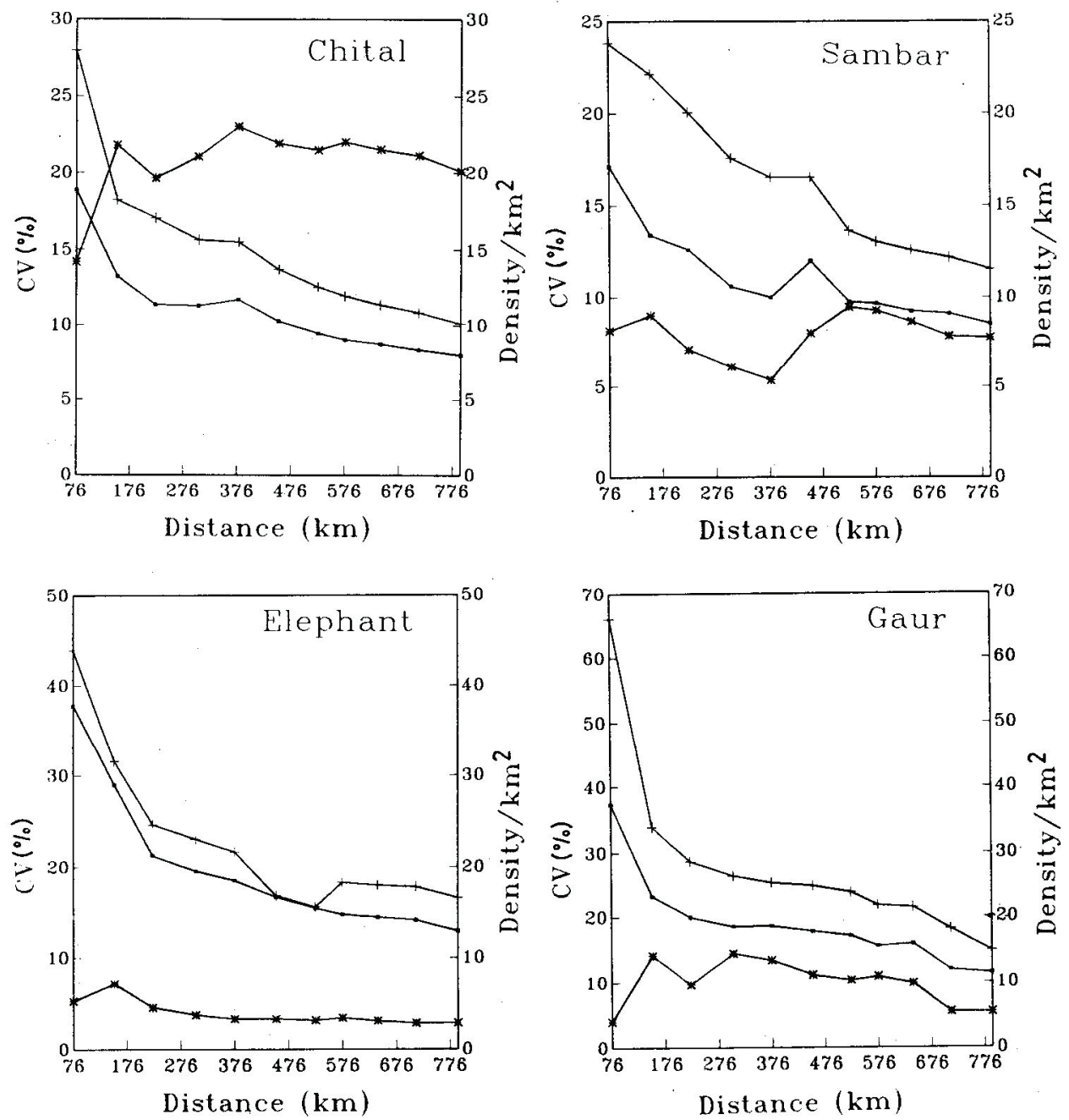

Figure 4. Trends in percentage coefficient of variation (CV) in group density $(-\bullet-)$ and individual density/ $\mathrm{km}_{2}(-+-)$ with sampling effort or transect distance $(\mathrm{km})$ for the four mammalian species. The mean individual densiiy $/ \mathrm{km}^{2}\left(-_{-}\right)$with varying sampling effort is also shown in the figure 
is achieved with a sampling effort of about $200 \mathrm{~km}$ of transects for chital and sarabar, while for elephant and gaur this is double and triple respectively. In order to achieve a $10 \% \mathrm{CV}$ (or a $95 \%$ CI of $20 \%$ of the mean), much higher sampling efforts are needed for alt (he species.

\subsection{Group size bias in detection}

The value of $\alpha$ is positive for all species indicating that there is a slight bias in detecting groups of different, sizes, with larger groups being detected more easily (table 3). However, for no species is this size-bias statistically significant. The value of $\alpha$ is also so small that there is little difference between density estimates obtained from the univariate and bivariate models.

\subsection{Comparison of densities between road-side and interior of forest}

A comparison of density estimates from walking and vehicle-based transects during 1991 are given in table 4. Differences in density estimates arise from significant

Table 2. Distance walked and number of detections for the four species.

\begin{tabular}{lcccc}
\hline $\begin{array}{l}\text { Distance } \\
\text { covered } \\
(\mathrm{km})\end{array}$ & Chital & Sambar & Elephant & Gaur \\
\hline 76 & 28 & 33 & 7 & 6 \\
153 & 57 & 57 & 19 & 19 \\
224 & 79 & 67 & 23 & 29 \\
304 & 110 & 85 & 27 & 37 \\
378 & 132 & 97 & 31 & 43 \\
453 & 165 & 132 & 38 & 46 \\
525 & 196 & 168 & 44 & 49 \\
576 & 207 & 181 & 49 & 61 \\
642 & 234 & 197 & 51 & 67 \\
713 & 257 & 203 & 53 & 77 \\
791 & 281 & 225 & 63 & 90 \\
\hline
\end{tabular}

Table 3. Influence of group size (size bias) in detection of animal groups.

\begin{tabular}{lccccccr}
\hline Species & $\begin{array}{c}\text { Sample } \\
\text { size }\end{array}$ & $\begin{array}{c}\text { Univariate } \\
(\text { model) density } \\
\left(\mathrm{km}^{-2}\right)\end{array}$ & $\begin{array}{c}\text { Size bias } \\
\text { parameter } \\
(\alpha)\end{array}$ & $\begin{array}{c}\text { Bivariate } \\
(\text { model }) \\
\text { density }\left(\mathrm{km}^{-2}\right)\end{array}$ & $\begin{array}{c}\text { Test statistic } \\
\text { (likelihood } \\
\text { ratio) }\end{array}$ & $\begin{array}{c}P . f . \\
\text { value }\end{array}$ \\
\hline Chital & 145 & 16.73 & 0.0654 & 15.87 & 1.23 & 1 & $>0.05$ \\
Sambar & 108 & 5.18 & 0.0987 & 4.87 & 1.22 & 1 & $>0.05$ \\
Elephant & 71 & 2.95 & 0.0903 & 2.84 & 0.73 & 1 & $>0.05$ \\
Gaur & 90 & 4.60 & 0.0460 & 4.42 & 0.34 & 1 & $>0.05$ \\
\hline
\end{tabular}

The data for chital and sambar arc based on 1 year (1991), while for elephant and gaur the data are combined for 1991-92.

Sample sizes refer to the number of groups sighted. 
Table 4. Density estimates from walking and vehicle based transects.

\begin{tabular}{|c|c|c|c|c|c|c|c|c|}
\hline Species & Mode & $\begin{array}{l}\text { Distance } \\
\text { covered } \\
(\mathrm{km})\end{array}$ & $\begin{array}{l}\text { Sample } \\
\text { size }\end{array}$ & $\begin{array}{c}\text { Mean } \\
\text { group } \\
\text { size } \pm S E\end{array}$ & $\begin{array}{c}\text { Group } \\
\text { density } \\
\left(\mathrm{km}^{-2}\right) \pm S E\end{array}$ & $\begin{array}{l}\text { Density of } \\
\text { individuals } \\
\left(\mathrm{km}^{-2}\right) \pm \mathrm{SE}\end{array}$ & $\begin{array}{c}\mathrm{Z} \\
\text { statistic }\end{array}$ & $\begin{array}{c}P \\
\text { value }\end{array}$ \\
\hline \multirow[t]{2}{*}{ Chital } & Walk & 321 & 115 & $608 \pm 0.64$ & $4.11 \pm 0.51$ & $25 \cdot 03 \pm 4.06$ & & \\
\hline & Vehicle & 967 & 339 & $10.59 \pm 0.84$ & $4.63 \pm 0.29$ & $49.02 \pm 5.03$ & 3.70 & $<0.01$ \\
\hline \multirow[t]{2}{*}{ Sambar } & Walk & 321 & 97 & $3.01 \pm 0.38$ & $2.20 \pm 0.22$ & $6.61 \pm 1.07$ & & \\
\hline & Vehicle & 967 & 49 & $3.92 \pm 0.66$ & $0.36 \pm 0.05$ & $1.42 \pm 0.32$ & 4.65 & $<0.01$ \\
\hline \multirow[t]{2}{*}{ Elephant } & Walk & 321 & 33 & $6.03 \pm 0.59$ & $0.73 \pm 0.13$ & $4.41 \pm 0.91$ & & \\
\hline & Vehicle & 967 & 45 & $5.28 \pm 0.73$ & $0.29 \pm 0.05$ & $1.54 \pm 0.34$ & 2.95 & $<0.01$ \\
\hline \multirow[t]{2}{*}{ Gaur } & Walk & 321 & 39 & $9.68 \pm 1.70$ & $1.49 \pm 0.29$ & $14.38 \pm 3 \cdot 80$ & & \\
\hline & Vehicle & 967 & 20 & $6.82 \pm 1.47$ & $0-08 \pm 0.02$ & $0.55 \pm 0.23$ & 3.63 & $<0.01$ \\
\hline
\end{tabular}

differences in density of groups and not of mean group sizes in the case of sambar, elephant and gaur, while in the case of chital these are due to significant differences in mean group sizes but not in density of groups.

The mean density of chital estimated from vehicle transects $\left(49 / \mathrm{km}^{2}\right)$ is twice that estimated from walking transects $\left(25 / \mathrm{km}^{2}\right)$ and is statistically significantly different. In the case of sambar, elephant and gaur, the estimates from vehicle transects are significantly lower than those from walking transects. The differences are particularly large in the case of gaur $\left(14 \cdot 4 / \mathrm{km}^{2}\right.$ from walking and $0 \cdot 5 / \mathrm{km}^{2}$ from vehicle) and sambar $\left(6 \cdot 6 / \mathrm{km}^{2}\right.$ from walking and $1 \cdot 5 / \mathrm{km}^{2}$ from vehicle).

The second approach of walking (as opposed to using vehicles) along roads versus walking in the interior of the adjacent forest also revealed similar significant differences in estimates (table 5a) for sambar $\left(11 \cdot 1 / \mathrm{km}^{2}\right.$ inside and $1 \cdot 3 / \mathrm{km}^{2}$ along roads), elephant $\left(3 \cdot 6 / \mathrm{km}^{2}\right.$ inside and $1.9 / \mathrm{km}^{2}$ along roads) and gaur $\left(4 \cdot 9 / \mathrm{km}^{2}\right.$ in forest and $1 \cdot 6 / \mathrm{km}^{2}$ along roads).

The results for chital $\left(15 \cdot 3 / \mathrm{km}^{2}\right.$ inside and $14 \cdot 9 / \mathrm{km}^{2}$ along roads) surprisingly show no difference, when the pooled data from all three zones sampled are considered. When the data for individual zones are examined (table 5b) it is seen that there are considerable differences between zones in chital densities along road-sides and interior. In some of the zones $(3 \mathrm{D}, 3 \mathrm{E})$ there seems to be a higher density along road-sides, as inferred from the higher number of sighting of groups per unit length of transect and higher mean group sizes, although differences are not necessarily statistically significant, in part due to low sample sizes. In another zone (8A) there actually seems to be a higher density of chital in the interior of the forest as compared to the road-sides, although the difference is not significant.

\section{Discussion}

\subsection{Choice of model parameters in data analysis}

On the basis of selecting a model with the greatest precision, the Fourier Series model gives estimates with the lowest percentage $\mathrm{CV}$, followed closely by the Half-Normal estimator. Estimated densities are comparable for the Fourier Series 
Table 5a. Density estimates along the road side and interior of forest,

\begin{tabular}{llccccccc}
\hline & & $\begin{array}{c}\text { Distance } \\
\text { covered } \\
(\mathrm{km})\end{array}$ & $\begin{array}{c}\text { Sample } \\
\text { size }\end{array}$ & $\begin{array}{c}\text { Mean group } \\
\text { size } \pm \mathrm{SE}\end{array}$ & $\begin{array}{c}\text { Group } \\
\text { density } \\
\left(\mathrm{km}^{-2}\right) \pm \mathrm{SE}\end{array}$ & $\begin{array}{c}\text { Density of } \\
\text { individuals } \\
\left(\mathrm{km}^{-2}\right) \pm \mathrm{SE}\end{array}$ & $\begin{array}{c}Z \\
\text { statistic }\end{array}$ & $\begin{array}{c}p \\
\text { value }\end{array}$ \\
\hline \multirow{2}{*}{ Chital } & Interior & 463 & 128 & $5.77 \pm 0.69$ & $2.66 \pm 0.27$ & $15.33 \pm 2.42$ & & \\
& Road side & 754 & 220 & $5.41 \pm 0.38$ & $2.75 \pm 0.21$ & $14.87 \pm 1.57$ & 0.16 & $>0.05$ \\
Sambar & Interior & 463 & 98 & $3.94 \pm 0.67$ & $2.81 \pm 0.33$ & $11.08 \pm 2.32$ & & \\
& Road side & 754 & 44 & $2.52 \pm 0.36$ & $0.50 \pm 0.07$ & $1.26 \pm 0.26$ & 4.21 & $<0.01$ \\
Elephant & Interior & 463 & 38 & $6.00 \pm 0.66$ & $0.60 \pm 0.09$ & $3.58 \pm 0.70$ & & \\
& Road side & 754 & 59 & $4.93 \pm 0.38$ & $0.38 \pm 0.09$ & $1.86 \pm 0.49$ & 2.01 & $<0.05$ \\
Gaur & Interior & 463 & 36 & $5.89 \pm 1.18$ & $0.84 \pm 0.13$ & $4.94 \pm 1.30$ &. & \\
& Road side & 754 & 29 & $6.19 \pm 1.71$ & $0.26 \pm 0.52$ & $1.58 \pm 0.55$ & 2.38 & $<0.05$ \\
\hline
\end{tabular}

b. Zone-wise comparison of density estimates for chital.

\begin{tabular}{|c|c|c|c|c|c|c|c|}
\hline Zone & $\begin{array}{c}\text { Distance } \\
\text { covered } \\
(\mathrm{km})\end{array}$ & $\begin{array}{c}\text { Sightings } \\
\text { (per } 10 \mathrm{~km})\end{array}$ & $\begin{array}{l}\text { Mean group } \\
\text { size } \pm S E\end{array}$ & $\begin{array}{l}\text { Group density } \\
\left(\mathrm{km}^{-2}\right) \pm S E\end{array}$ & $\begin{array}{l}\text { Density of } \\
\text { individuals } \\
\left(\mathrm{km}^{-2}\right) \pm \mathrm{SE}\end{array}$ & $\begin{array}{c}\text { Z } \\
\text { statistic }\end{array}$ & $\begin{array}{c}P \\
\text { value }\end{array}$ \\
\hline 3E Interior & 214 & 2.80 & $3.47 \pm 0.70$ & $3.81 \pm 0.50$ & $13.22 \pm 3.19$ & & \\
\hline 3E Road side & 378 & 3.78 & $5.54 \pm 0.56$ & $3.40 \pm 0.30$ & $18.86 \pm 2.53$ & 1.39 & $p>0.05$ \\
\hline 3D Interior & 112 & 0.45 & $3.00 \pm 0.97$ & $-\quad-$ & $-\quad-$ & - & \\
\hline 3D Road side & 240 & 1.42 & $3.34 \pm 0.51$ & $2.09 \pm 0.36$ & $6.98 \pm 1.61$ & - & \\
\hline $3 \mathrm{C}$ Interior & 58 & 0.34 & - & - & -- & - & \\
\hline 3C Road side & 58 & 0.00 & -- & $-\quad-$ & $-\quad-$ & - & \\
\hline 8A Interior & 68 & 9.41 & $7 \cdot 42 \pm 1.19$ & $7 \cdot 70 \pm 1 \cdot 13$ & $57 \cdot 16 \pm 12 \cdot 51$ & - & \\
\hline 8A Road side & 58 & 8.28 & $6.39 \pm 0.78$ & $5.21 \pm 0.79$ & $33.28 \pm 6.53$ & 1.69 & $P>0.05$ \\
\hline
\end{tabular}

Blanks indicate low sample size for valid statistical analysis.

and Half-Normal models. The Negative Exponential model appears to give consistently high density estimates for most species; this may be suitable for a species such as muntjac (Muntiacus muntjak) (Karanth 1988) which we did not examine. Although it appears intuitively unlikely that the detection curve for a large mammal such as gaur could be modelled by the Negative Exponential, this model did fit the data well in our case.

Several models appear comparable when adequacy is judged on the basis of the $\chi^{2}$ goodness of fit test. However, the Half-Normal model consistently gives a good fit to data for chital, while its fit is particularly poor for gaur. Grouping data into different number of distance classes seems to make no obvious difference in density estimates and their CVs. If model fit is to be evaluated by the $\chi^{2}$ tests, grouping into fewer classes seems to be the better option, probably because the data are smoothed. This would also ensure that, with relatively low sample sizes, each class has greater than five observations which is a general recommendation for the $\chi^{2}$ test to be valid. This may however not be of any practical advantage in data analysis, as similar results are obtained in all cases. 
$\chi^{2}$ tests of model fit have limitations in selection of models or data grouping criteria (Burnham et al 1980). Depending upon the selection of number of groups and group intervals, the same field data can show either model fit or lack of fit. Thus, Burnham et al (1980) state that other criteria such as model robustness (flexibility in fitting a variety of true underlying probability density functions), pooling robustness (robust to pooling of data collected under variations in habitat, climatic conditions, observer and so on) and estimator efficiency (precision) must be used in model selection.

Assuming that the Fourier series is a robust model, as recommended by Burnham et al (1980) and used by Karanth and Sunquist (1992) in a forest type similar to that of our study area, our experiments with various cut-off widths revealed the following patterns. For chital, a species which is reasonably abundant and whose small body size makes detection at large distances relatively difficult, it is not very useful to include sightings beyond about $100 \mathrm{~m}$, since there is no increase in precision. This could be an appropriate cut-off width for making density estimates. With our data this involved removing 3\% cases of outliers. In the case of sambar and elephant a cut-off width of $140 \mathrm{~m}$ seemed to be appropriate. For gaur the results are more ambiguous; it may be necessary to try various cut-off distances before arriving at a suitable one. For the less abundant species the need to have an adequate sample size may influence this decision.

\subsection{Sampling effort and precision of estimate}

The precision of the estimate (CV) would improve with increased sample size (which translates into sampling effort). Sampling effort needed to achieve a desired precision would vary with species and location, depending on their abundance, variation in group size and detectability. In general, a substantial effort is needed in achieving a $<20 \% \mathrm{CV}$ on mean estimates for species with densities under 10 individuals $/ \mathrm{km}^{2}$. The $95 \%$ confidence limits would be even higher than the CV; a $20 \%$ CV translates into a $95 \%$ CI of nearly $40 \%$ of the mean. Thus, a sample size of 40 sightings considered as adequate for line transect analysis (Burnham et al 1980 ) results in an $18-20 \% \mathrm{CV}$ on mean density estimate (or a $95 \%$ CI of $36-40 \%$ of the mean) for chital, sambar and elephant, and still higher for gaur. It is therefore unlikely that changes in the population of a species can be detected with statistical confidence over short time periods, if such changes are of smaller magnitude. All census programmes for mammals should consider this even before embarking on the field exercises.

\subsection{Size bias in detection of groups}

The lack of statistically significant size-bias indicates that univariate models are usually adequate for estimating densities of these mammals. Bivariate models are called for only when there is definite evidence for size-bias in detection. Karanth (1988) detected size bias for chital but not for sambar, elephant and gaur. It is possible that with very high sample sizes even a slight bias in detection (low $\alpha$ value) would be statistically significant. This would not result in major differences in density estimates. 


\subsection{Use of roads in sampling}

There is clearly significant bias in density estimates obtained from road-side counts for all species in Mudumalai Sanctuary. It is well known that chital prefer the ecotones of forest-grassland and open habitats. It can thus be expected that the density of chital would be higher along road-sides where artificial clearing is resorted to for increasing visibility for the benefit of tourists. As anticipated we found that the density estimates of chital from vehicle counts are double that from transects walked in the interior of the forest. However, the results from walking along roads as opposed to walking transects inside the forest near these roads are rather intriguing. It seems as though there are habital-specific differences in the spatial distribution of chital. In zones with a relatively dense undergrowth of saplings or grass, chital may avoid the interior of forest and congregate along road-side clearings. In habitats where the undergrowth is more open and has shorter grasses, a very high density of chital may be responsible for their similar abundances along road-sides and interiors of forest.

Sambar. elephants and gaur clearly avoid road-sides, probably because of disturbance from vehicular traffic in the sanctuary. The roads we sampled include highways as well as roads frequented by tourists during the same time-period as our sampling. These results may not hold good for all the species in areas where vehicular traffic is infrequent. Sambar may also prefer denser habitat during the day and hence avoid road-side clearings (Varman and Sukumar 1993).

\section{Acknowledgements}

This study was funded by the Ministry of Environment and Forests, New Delhi. We thank the Forest Department of Tamil Nadu for permission to carry out the research in Mudumalai Sanctuary. We also thank $\mathrm{R}$ Arumugam and $\mathrm{N}$ Rai for collecting a part of the field data, and C M Annadurai, Sivaji and R Mohan for field assistance. DГ N V Joshi provided critical comments on our analyses and the manuscript.

\section{References}

Anderson D R, Laake J L. Crain B R and Buraham K V 1979 Guidelines for line transect sampling of biological populations; J. Wildl. Manage. 43 70-78

Barnes R E W and Jensen K L 1987 How to count elephants in forests; IUCN African Elephant and Rhino Specialist Group Technical Bulletin 1 1-6

Burnham K P, Anderson D R and Laake J L 1980 Estimation of density from line transect sampling of biological populations; Wildl. Monogr. 72 1-202

Buckland S T, Anderson D R, Burnham K P and Laake J L 1993 Distance sampling: Estimating abundance of biological populations (London: Chapman and Hall)

Drummer T 1987 Program dncumentation und user's guide far SIZETRAN (Houghton, Michigan. Michigan Technological University)

Drummer T D and McDonald L L 1987 Sue bias in line transect sampling; Biometrics 43 13-21

Goodman L A 1960 On the exact variance of products; J. Am. Statist. Assioc. 708-713

Karanth K U 1988 Population structure, density and biomass of large herbivores in a south Indian tropical forest. MS dissertation. University of Florida, Gainesville, USA

Karanth K U and Sunquist M E 1992 Population structure, density and biomass of large herbivores in the tropical forests of Nagarahole, India; J. Trop, Ecol. 8 21-35 
Krishnan M 1972 An ecological survey of the larger mammals of peninsular India (Bombay: Bombay Natural History Society)

Koster S H and Han J A 1988 Methods of estimating ungulate population in tropical forests; Afr. J. Ecol. 26 117-126

Laake J L. Burnham K P and Anderson D R 1979 User manual of program TRANSECT (Logan: Ulah Stale University Press;) pp 26

Nair S S, Nair P V K. Sharaiuhandra H C and Gadgil M 1976 An ecological reconnaissance of the proposed Jawahar National Park; J. Bombay Nat. Him. Soc. 74 401-135

Sale J B, Johnsingh A J T, Dawson S 1990 Preliminary trials with an indirect method of estimating Asian elephant numbers (IUCN/SSC Asian Elephant Specialist Group Report)

Sukumar R, Daltaraja H S, Suresh H S, Radhkikrishnan, J. Vasudeva R, Nirmala S and Joshi N V 1992 Long-term monitoring of vegetation in a tropical deciduous forest in Mudumalai. southern India: Curr. Sci. 62 608-616

Varman K . S 1988 A study on census of large mammals and their habitat utilization during dry season in Mudumalai Wildlife Sanctuary, M. Sc. dissertation, Bharalhidasan University. Tiruchirapalli

Varman K S and Sukumar R 1993 Ecology of sambar in Mudumalai Sanctuary, southern India; in Deer of China: Biology and management (eds) N Ohtaishi and H I Shen (Amsterdam: Elsevier Science Publishers) pp 273-284

Varman K S. Ramakrishnan U and Sukumar R 1995 Direct and indirect methods of counting elephants: a comparison of results from Mudumalai mudumalai Sanctuary: in Proc. International Workshop on Conservation of Asian Elephants (ed.) J C Daniel (Bombay: Bombay Natural History Society) (in press) 